\title{
Short communication: Analytical method and amount of preservative added to milk samples may alter milk urea nitrogen measurements
}

\author{
Holley L. Weeks and Alexander N. Hristov ${ }^{1}$ \\ Department of Animal Science, The Pennsylvania State University, University Park 16802
}

\begin{abstract}
Milk urea N (MUN) is used by dairy nutritionists and producers to monitor dietary protein intake and is indicative of $\mathrm{N}$ utilization in lactating dairy cows. Two experiments were conducted to explore discrepancies in MUN results provided by 3 milk processing laboratories using different methods. An additional experiment was conducted to evaluate the effect of 2-bromo-2-nitropropane-1, 3-diol (bronopol) on MUN analysis. In experiment 1, 10 replicates of bulk tank milk samples, collected from the Pennsylvania State University's Dairy Center over 5 consecutive days, were sent to 3 milk processing laboratories in Pennsylvania. Average MUN differed between laboratory A $(14.9 \pm 0.40$ mg/dL; analyzed on MilkoScan 4000; Foss, Hillerød, Denmark), laboratory B $(6.5 \pm 0.17 \mathrm{mg} / \mathrm{dL}$; MilkoScan $\mathrm{FT}+6000)$, and laboratory C $(7.4 \pm 0.36 \mathrm{mg} / \mathrm{dL}$; MilkoScan 6000). In experiment 2, milk samples were spiked with urea at $0(7.3$ to $15.0 \mathrm{mg} / \mathrm{dL}$, depending on the laboratory analyzing the samples), 17.2, 34.2, and $51.5 \mathrm{mg} / \mathrm{dL}$ of milk. Two $35-\mathrm{mL}$ samples from each urea level were sent to the 3 laboratories used in experiment 1. Average analyzed MUN was greater than predicted (calculated for each laboratory based on the control; $0 \mathrm{mg}$ of added urea): for laboratory A (23.2 vs. $21.0 \mathrm{mg} / \mathrm{dL})$, laboratory B (18.0 vs. $13.3 \mathrm{mg} / \mathrm{dL})$, and laboratory C (20.6 vs. $15.2 \mathrm{mg} / \mathrm{dL})$. In experiment 3, replicated milk samples were preserved with 0 to 1.35 $\mathrm{mg}$ of bronopol $/ \mathrm{mL}$ of milk and submitted to one milk processing laboratory that analyzed MUN using 2 different methods. Milk samples with increasing amounts of bronopol ranged in MUN concentration from 7.7 to $11.9 \mathrm{mg} / \mathrm{dL}$ and from 9.0 to $9.3 \mathrm{mg} / \mathrm{dL}$ when analyzed on MilkoScan 4000 or CL 10 (EuroChem, Moscow, Russia), respectively. In conclusion, measured MUN concentrations varied due to analytical procedure used by milk processing laboratories and were affected by the amount of bronopol used to preserve milk sample, when milk was analyzed using a mid-infrared analyzer.
\end{abstract}

Received April 5, 2016.

Accepted October 23, 2016.

${ }^{1}$ Corresponding author: anh13@psu.edu
Thus, it is important to maintain consistency in milk sample preservation and analysis to ensure precision of MUN results.

Key words: milk urea nitrogen, bronopol, dairy cow

\section{Short Communication}

Indicators for monitoring dietary $\mathrm{N}$ adequacy in dairy cattle include BUN, urinary urea N, and MUN. Of these, MUN is the most practical analysis because individual cow or bulk tank milk samples are routinely collected on dairy farms (Roy et al., 2011). Milk urea $\mathrm{N}$ is used to monitor dietary $\mathrm{CP}$ and $\mathrm{N}$ utilization in lactating cows and is linearly related to urinary $\mathrm{N}$ excretion (Broderick and Clayton, 1997; Hof et al., 1997). High MUN levels can indicate excess CP or RDP in the diet, which could increase $\mathrm{N}$ excretion and ammonia emission from manure, may have negative effects on reproduction, and also increase feed costs to the producer (Nousiainen et al., 2004; Burgos et al., 2007; Lean et al., 2012). It should be pointed out, however, that some analyses have shown no relationship between individual cow milk urea concentration and reproduction in dairy cows on pasture (Trevaskis and Fulkerson, 1999), or bulk tank MUN and ammonia emissions from manure (Weeks et al., 2015). Jonker et al. (2002b) concluded that farms provided with their bulk tank MUN data on a monthly basis for $6 \mathrm{mo}$ had $0.52 \mathrm{mg} / \mathrm{dL}$ lower MUN than farms who did not received their bulk tank MUN data over the course of their study. This decrease in MUN resulted from an $11 \mathrm{~g} / \mathrm{d}$ per cow decrease in $\mathrm{N}$ intake. Milk analysis laboratories use different analytical equipment and methods for MUN analysis, which can result in variability in MUN data (Arunvipas et al., 2003; Kohn et al., 2004). This can, in turn, cause confusion on how MUN for a particular farm ranks relative to optimal MUN values suggested in the literature (for example, Jonker et al., 2002a; Powell et al., 2014). Therefore, the objectives of this study were to (1) investigate consistency among laboratories' MUN analytical methods, and (2) investigate differences in MUN due to milk preservative added.

In experiment 1, bulk tank milk samples were collected from the Pennsylvania State University's Dairy 
Research and Teaching Center herd. After 5 min of continuous agitation, six $35-\mathrm{mL}$ milk samples were collected at $1400 \mathrm{~h}$ daily over $5 \mathrm{~d}$. Two samples from each day were shipped overnight to 3 milk processing laboratories (laboratories A, B, and C) to be analyzed for MUN, milk fat, and milk true protein (see Table 1). Milk samples were analyzed by mid-infrared spectroscopy at laboratory A using MilkoScan 4000 (MS; Foss, Hillerød, Denmark), at laboratory B using MilkoScan FT +6000 (Foss), and at laboratory C using MilkoScan 6000 (Foss). Samples from 4 of the $5 \mathrm{~d}$ submitted to laboratory A were also analyzed for MUN using a CL 10 analyzer (CL; EuroChem, Moscow, Russia), according to procedures described by Luzzana and Giardino (1999). The CL 10 method is considered the standard to which other methods are compared due to its accuracy (Dairy One Cooperative Inc., Ithaca, NY, personal communication). Milk samples sent to laboratory A and laboratory $\mathrm{B}$ were preserved with 2-bromo-2-nitropropane-1, 3-diol (bronopol, Janssen Pharmacauticalaan, Beerse, Belgium). Milk samples sent to laboratory C were shipped refrigerated and without preservative due to the inability of laboratory C's equipment to analyze milk preserved with bronopol. Milk MUN data were analyzed using the MEANS and MIXED procedures of SAS (version 9.4; SAS Institute Inc., 2003). The MIXED model contained milk sampling day, laboratory, and sampling day $\times$ laboratory interaction, and data were analyzed as repeated measures assuming an $\operatorname{AR}(1)$ covariance structure. When the main effect of laboratory was significant $(P \leq 0.05)$, means were separated by pairwise $t$-test (pdiff option of PROC MIXED).

In experiment 2, a 2-L bulk tank milk sample was collected from The Pennsylvania State University's Dairy Research and Teaching Center on a single day following
5 min of continuous agitation in the cooling tank. The $2 \mathrm{~L}$ of milk were divided into four 500-mL samples. Samples were spiked with urea at $0,17.2,34.2$, and $51.5 \mathrm{mg}$ urea/dL milk (i.e., added urea levels control, 1 , 2 , and 3 , respectively). Two $35-\mathrm{mL}$ samples from each urea level were preserved and sent to laboratories A, $\mathrm{B}$, and $\mathrm{C}$ for MUN analysis according to the methods listed for experiment 1 (Table 1). Based on the amount of added urea and the analyzed MUN concentration of the control milk samples ( $0 \mathrm{mg}$ of added urea/dL) from each laboratory, expected MUN concentrations were calculated for each laboratory and each urea level (i.e., concentration of MUN in control milk sample plus amount of added urea for levels 1, 2, and 3). Data in experiment 2 were analyzed using the MIXED procedure of SAS. The model contained laboratory, urea level, and laboratory $\times$ urea level interaction. Similar to experiment 1 , when the main effect of laboratory was significant $(P \leq 0.05)$, means were separated by pairwise $t$-test (pdiff option of PROC MIXED).

In experiment 3, 48 milk vials were prepared with 16 levels (0 to $1.35 \mathrm{mg} / \mathrm{mL}$ ) of bronopol (Janssen Pharmacauticalaan). Bronopol was added as $15 \%$ aqueous solution. Each bronopol level was replicated 3 times. A 2-L bulk tank milk sample was collected from The Pennsylvania State University's Dairy Research and Teaching Center following the procedure outlined for experiments 1 and 2. Thirty-five $\mathrm{mL}$ of milk was added to each vial, resulting in final bronopol concentrations of $0,0.10,0.19,0.29,0.38,0.47,0.54,0.65,0.72,0.80$, $0.91,0.98,1.07,1.16,1.24$, and $1.35 \mathrm{mg} / \mathrm{mL}$. All milk vials were sent to laboratory A for MUN analysis using mid-infrared spectroscopy on a MilkoScan 4000 (Foss) and a CL 10 analyzer. Data in experiment 3 were analyzed using the MIXED procedure of SAS with bronopol concentration in the model and contrasts to

Table 1. Experimental procedures and sample preparation used in the study ${ }^{1}$

\begin{tabular}{|c|c|c|c|c|}
\hline Item & $\begin{array}{l}\text { Laboratory } \\
\text { A-MS }\end{array}$ & $\begin{array}{l}\text { Laboratory } \\
\text { A-CL }\end{array}$ & $\begin{array}{l}\text { Laboratory } \\
\text { B }\end{array}$ & $\begin{array}{l}\text { Laboratory } \\
\mathrm{C}\end{array}$ \\
\hline \multicolumn{5}{|l|}{ Experiment 1} \\
\hline Equipment used & MilkoScan 4000 & CL 10 & MilkoScan FT + 6000 & MilkoScan 6000 \\
\hline Refrigerated & Yes & Yes & No & Yes \\
\hline Analytical procedure & Infrared analyzer & Wet chemistry & Infrared analyzer & Infrared analyzer \\
\hline \multicolumn{5}{|l|}{ Experiment $2^{2}$} \\
\hline \multirow{2}{*}{\multicolumn{5}{|c|}{ Experiment $3^{2}$}} \\
\hline & & & & \\
\hline Bronopol added at 0 to $1.35 \mathrm{mg} / \mathrm{mL}$ of milk & Analyzed & Analyzed & Not analyzed & Not analyzed \\
\hline
\end{tabular}

${ }^{1} \mathrm{MS}=$ MilkoScan (Foss, Hillerød, Denmark); CL = CL 10 (EuroChem, Moscow, Russia); bronopol (Janssen Pharmacauticalaan, Beerse, Belgium).

${ }^{2}$ Method of analysis, equipment, and sample preparation as in experiment 1 . 
Table 2. Average MUN, milk fat, and milk true protein concentrations in milk samples analyzed by laboratories A, B, and C (experiment $1^{1}$ )

\begin{tabular}{|c|c|c|c|c|c|c|}
\hline Item & $\begin{array}{c}\text { Laboratory } \\
\mathrm{A}-\mathrm{MS}^{2}\end{array}$ & $\begin{array}{c}\text { Laboratory } \\
\mathrm{A}-\mathrm{CL}^{2}\end{array}$ & $\begin{array}{c}\text { Laboratory } \\
\text { B }\end{array}$ & $\begin{array}{c}\text { Laboratory } \\
\text { C }\end{array}$ & SEM & $P$-value ${ }^{3}$ \\
\hline Mean MUN, mg/dL & $14.9^{\mathrm{a}}$ & $14.5^{\mathrm{a}}$ & $6.5^{\mathrm{c}}$ & $7.4^{\mathrm{b}}$ & 0.32 & $<0.001$ \\
\hline $\mathrm{SD}$ & 1.56 & 0.26 & 0.43 & 0.63 & & \\
\hline Maximum & 17.3 & 14.9 & 7.2 & 8.4 & & \\
\hline $\mathrm{CV}$ & 10.5 & 1.8 & 6.7 & 8.5 & & \\
\hline Mean milk fat, $\%$ & $3.69^{\mathrm{a}}$ & - & $3.55^{\mathrm{c}}$ & $3.58^{\mathrm{b}}$ & 0.003 & $<0.001$ \\
\hline $\mathrm{CV}$ & 3.6 & & 2.3 & 2.0 & & \\
\hline Mean true protein, $\%$ & $3.17^{\mathrm{b}}$ & - & $3.18^{\mathrm{a}}$ & $3.16^{\mathrm{b}}$ & 0.004 & 0.01 \\
\hline SD & 0.029 & - & 0.046 & 0.038 & & \\
\hline Minimum & 3.11 & - & 3.10 & 3.10 & & \\
\hline Maximum & 3.20 & - & 3.25 & 3.20 & & \\
\hline $\mathrm{CV}$ & 3.1 & - & 1.4 & 1.2 & & \\
\hline
\end{tabular}

${ }^{\mathrm{a}-\mathrm{c}}$ Means within a row having different letter superscripts differ at $P \leq 0.05$.

${ }^{1}$ Mean values in table are LSM; $\mathrm{n}=38$ (MUN) and 30 (milk fat and protein), $\mathrm{n}$ represents the number of observations used in the statistical analysis.

${ }^{2}$ Laboratory A analyzed MUN using 2 methods: MilkoScan 4000 (MS; Foss, Hillerød, Denmark) and CL 10 (CL, EuroChem, Moscow, Russia); see Table 1 for details. Laboratory B used MilkoScan FT +6000 and laboratory C used MilkoScan 6000.

${ }^{3}$ Main effect of laboratory. MUN data: effect of day of milk sampling, $P=0.76$; laboratory $\times$ day of milk sampling interaction, $P=0.22$; milk fat data: effect of day of milk sampling, $P<0.001$; laboratory $\times$ day of milk sampling interaction, $P=0.03$; milk true protein data: effect of day of milk sampling, $P<0.001$; laboratory $\times$ day of milk sampling interaction, $P=0.10$.

evaluate linear and quadratic effects of bronopol concentration.

The objective of experiment 1 was to set baseline MUN concentrations and determine differences in MUN analysis among laboratories. Average MUN concentration analyzed at laboratory A was greater $(P<0.001)$ than laboratories $\mathrm{B}$ and $\mathrm{C}$, as shown in Table 2. The 2 methods used by laboratory A, MilkoScan 4000 and CL 10, returned similar MUN values. Average MUN concentration for laboratory $\mathrm{C}$ was also greater $(P<$ 0.001 ) than laboratory B. There was no effect of day of milk sampling $(P=0.76)$ and there was no day of sampling $\times$ laboratory interaction $(P=0.22)$ for MUN. Variability in MUN data (SD and CV) was larger for laboratory A (MS method) than B and C. The lowest variability was associated with the CL method (laboratory A). As shown in Table 2, the 3 laboratories returned different results for milk fat and true protein $(P \leq 0.01)$ concentrations, although differences were subtle, particularly for milk protein. Kohn et al. (2004) concluded that $34 \%$ of the variation in bulk tank MUN for Foss (MilkoScan) 4000 was attributed to laboratory. In their study, milk samples analyzed on Foss 4000 resulted in the largest $\mathrm{SD}( \pm 2.51 \mathrm{mg} / \mathrm{dL})$ when compared with CL 10. Conversely, the Bentley $( \pm 0.45 \mathrm{mg} /$ $\mathrm{dL})$, Foss $6000( \pm 0.62 \mathrm{mg} / \mathrm{dL})$, and Skalar $( \pm 0.55 \mathrm{mg} /$ $\mathrm{dL}$ ) instruments resulted in smaller SD when compared with CL 10 (Kohn et al., 2004). Similarly, Peterson et al. (2004) concluded that the highest variation among methods occurred with the Foss 4000 analyzer and the lowest variation with the CL 10. In the present study, average MUN concentrations differed between laboratories A (MilkoScan 4000), B (MilkoScan FT+ 6000), and C (MilkoScan 6000), likely due to variation in analytical procedure and equipment (Arunvipas et al., 2003; Kohn et al., 2004). If a theoretical benchmark for MUN is assumed at 10 to $12 \mathrm{mg} / \mathrm{dL}$ (Jonker et al., 2002a; Powell et al., 2014), the present study indicated that MUN results from laboratory A are above the benchmark and results from laboratories B and C are below the benchmark for identical milk samples. Thus, data from experiment 1 indicate that laboratory and analytical method may cause significant variability in bulk tank MUN data.

The objective of experiment 2 was to quantify the accuracy of each laboratory's MUN analysis. Average analyzed MUN and the difference between analyzed and predicted MUN are presented in Table 3. The difference between analyzed and expected (calculated based on MUN concentration in the control milk samples for each laboratory and the amount of added urea) MUN concentration was largest $(P<0.001)$ for laboratory $\mathrm{C}$ followed by laboratory $\mathrm{B}$, and was least for laboratory $\mathrm{A}$. The difference was clearly increasing $(P<$ 0.001) for all laboratories with increasing the amount of added urea, but the ranking among laboratories remained the same. The relationship between amount of added urea and the difference between analyzed and predicted MUN was linear for all laboratories $\left(\mathrm{R}^{2}=\right.$ 0.82 to $0.99 ; P \leq 0.001)$. Peterson et al. (2004) com- 
pared recovery of urea $\mathrm{N}$ among 5 analytical methods: Bentley, CL 10, Foss 4000, Foss 6000, and Skalar using milk samples from 100 individual cows. Recovery by CL $10(85.0 \pm 2.76 \%)$ was lower than for Bentley, Foss 6000 , and Skalar, but greater compared with Foss $4000(47.1 \pm 9.88 \%)$. Furthermore, no differences were detected for Bentley and CL 10 among laboratories; however, results for Foss 4000, Foss 6000, and Skalar varied among laboratories. In the present study, all 3 laboratories overestimated MUN compared with the expected concentrations, but the least overestimation was for laboratory A, which used MilkoScan 4000. An important point in any analysis, including MUN, is calibration of the analytical equipment. All laboratories have established calibration procedures but as pointed out by Kohn et al. (2004), better calibration methods across laboratories may improve the consistency of MUN results. In experiment 2 of the current study, the range of calibration standards used by the laboratories may have not been adequate to cover the range of MUN in the milk samples with added urea.

The objective of experiment 3 was to determine the effect of increasing concentrations of bronopol on MUN as analyzed by laboratory A using 2 MUN methods (MilkoScan 4000 and CL 10). Data from this experiment are shown in Figure 1. Concentration of MUN analyzed on MilkoScan 4000 ranged from 7.7 to 11.9 $\pm 0.27 \mathrm{mg} / \mathrm{dL}$ and linearly increased $(P<0.001)$ with increasing bronopol concentration. Milk urea $\mathrm{N}$ concentrations analyzed on CL 10 ranged from 9.0 to $9.3 \pm$
$0.05 \mathrm{mg} / \mathrm{dL}$ and tended to increase linearly $(P=0.06)$ with increasing bronopol concentration. MilkoScan 4000 uses mid-infrared spectroscopy, in which a beam of light at specified wavelength for the component being measured is passed through milk and the amount of light absorbed is measured (Arunvipas et al., 2003). Data for MilkoScan 4000 from experiment 3 suggest that the absence of bronopol in experiment 1, laboratory $\mathrm{C}$ milk samples may have resulted in lower MUN values than if those samples contained bronopol. In the CL 10 method, the amount of ammonia formed from urea after hydrolysis with urease is used to calculate MUN (Arunvipas et al., 2003; Kohn et al., 2004). Previous studies indicate greater variability with MilkoScan 4000 compared with CL 10 for multiple laboratories (Kohn et al., 2004; Peterson et al., 2004). Conversely, Arunvipas et al. (2003) reported high reliability and repeatability for both MilkoScan 4000 and CL 10 when analyzed at a single laboratory. In the present study, bronopol concentration of $0.54 \mathrm{mg} / \mathrm{mL}$ analyzed on MilkoScan 4000 resulted in about $12 \%$ greater $(P$ $<0.05)$ MUN than the control $(9.6$ vs. $8.5 \mathrm{mg} / \mathrm{dL}$, respectively). According to one milk processing laboratory, recommended bronopol concentration is $0.085 \%$, which is $0.85 \mathrm{mg} / \mathrm{mL}$ of milk (Dairy One Cooperative Inc., personal communication). At this concentration, and based on data from experiment 3 with MilkoScan 4000 (Figure 1), MUN concentration would likely be overestimated by about $30 \%$. Some have suggested that bronopol should be used to preserve milk samples at

Table 3. MUN concentrations in milk samples with added urea (experiment $2^{1}$ )

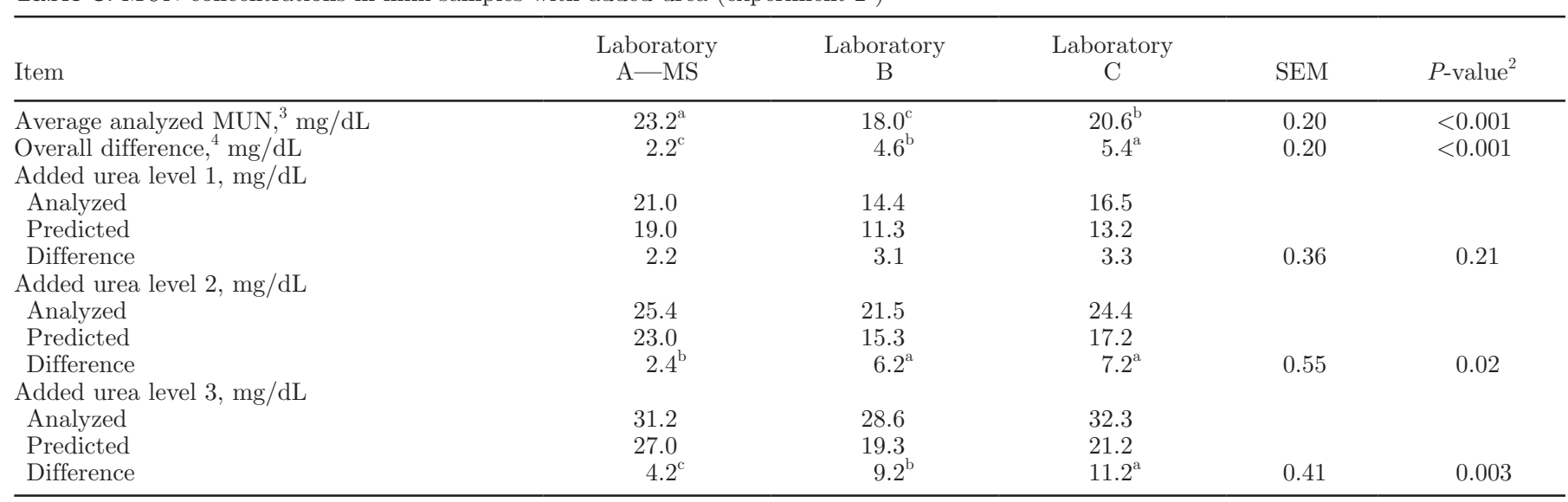

${ }^{a-c}$ Means within a row having different letter superscripts differ at $P \leq 0.05$.

${ }^{1}$ Difference data are LSM; $\mathrm{n}=24$ (analyzed MUN) and 6 (added urea levels $1-3$ ), $\mathrm{n}$ represents the number of observations used in the statistical analysis.

${ }^{2}$ Main effect of laboratory.

${ }^{3}$ Average MUN across added urea levels. Effect of added urea level, $P<0.001$; laboratory $\times$ added urea level interaction, $P<0.001$.

${ }^{4}$ Difference between analyzed and expected MUN concentrations (analyzed - expected MUN) across added urea levels. Expected MUN concentrations were calculated from amount of urea added and MUN of the control samples from each laboratory. Added urea levels: control $=0$, level $1=17.2$, level $2=34.2$, and level $3=51.5 \mathrm{mg}$ of urea/dL of milk. Differences between analyzed and expected MUN concentrations were close to zero $\left(10^{-32}\right.$ to $\left.9^{-16} \mathrm{mg} / \mathrm{dL}\right)$ for the control (i.e., $0 \mathrm{mg}$ of added urea) samples. 


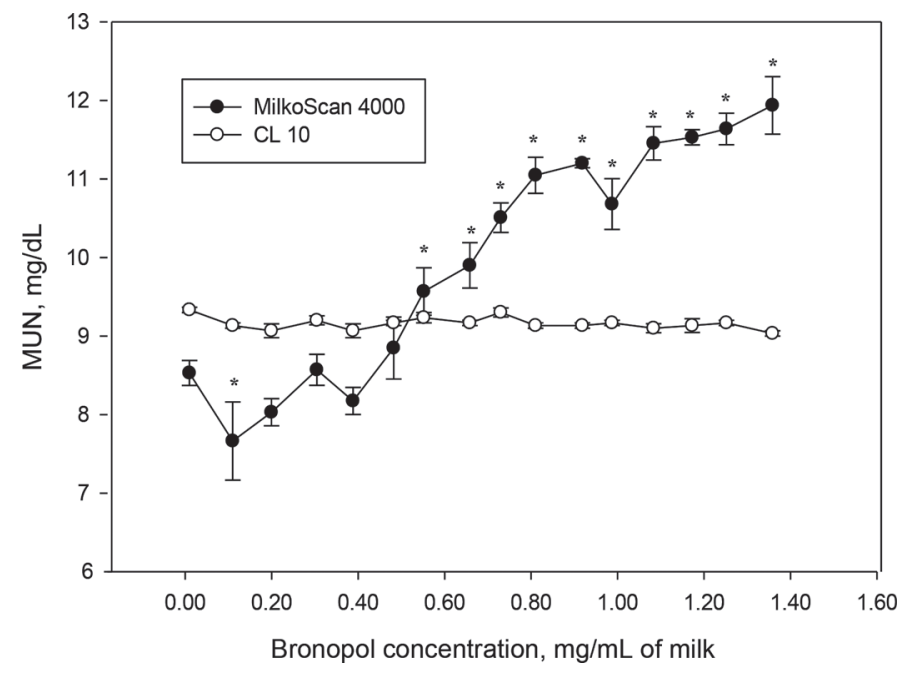

Figure 1. Average MUN concentration $( \pm \mathrm{SE})$ in milk preserved with increasing concentrations of bronopol (Janssen Pharmacauticalaan, Beerse, Belgium) analyzed at laboratory A-MS (MilkoScan 4000, Foss, Hillerød, Denmark) and laboratory A-CL (CL 10, EuroChem, Moscow, Russia; experiment 3). Effect of bronopol concentration: linear $P<0.001$ (MilkoScan 4000) and $P=0.06$ (CL 10). *Indicates significant difference $(P<0.05)$ between control $(0 \mathrm{mg}$ of bronopol $)$ and specified concentration of bronopol when analyzed on MilkoScan 4000. Data are arithmetic means.

concentrations of 0.01 to $0.02 \%$ (Barbano et al., 2010), or 0.1 to $0.2 \mathrm{mg} / \mathrm{mL}$. At these low concentrations, MUN analysis is likely not going to be affected by bronopol (Figure 1). It is noted that MUN analysis by CL 10 was more consistent and was less affected by bronopol concentration. The CL 10 is widely accepted as the most accurate measurement of MUN; however, due to cost and additional labor needed to analyze samples, it is not practical for commercial use (Arunvipas et al., 2003). We are not aware of published data on bronopol interference with MUN analysis. Other milk components, such as fat, protein, and SCC, do interfere with the mid-infrared analysis of MUN (Arunvipas et al., 2003), but the calibration process and computer algorithm correct for these interferences. Barbano et al. (2010) studied various milk preservatives and reported that bronopol-based preservatives interfered with midinfrared analyses, particularly for milk protein, compared with $\mathrm{K}_{2} \mathrm{Cr}_{2} \mathrm{O}_{7}$-preserved milk.

Milk urea $\mathrm{N}$ is widely used on farm as an indicator of dietary $\mathrm{CP}$ and RDP concentrations, intake, and $\mathrm{N}$ utilization in dairy cows. Data from the current experiments indicate that reported MUN concentrations vary between laboratories depending on method and equipment used. When analyzed by a mid-infrared ana- lyzer, MUN concentration may also be affected by the concentration of bronopol used. Consistently using the same laboratory and sampling procedure is advisable, if MUN concentration (bulk tank or individual cows) is used to monitor protein status of the herd. Thus, establishing a MUN benchmark relative to the laboratory and analytical method used may be helpful for on-farm management purposes.

\section{REFERENCES}

Arunvipas, P., J. A. VanLeeuwen, I. R. Dohoo, and G. P. Keefe. 2003. Evaluation of the reliability and repeatability of automated milk urea nitrogen testing. Can. J. Vet. Res. 67:60-63.

Barbano, D. M., K. L. Wojciechowski, and J. M. Lynch. 2010. Effect of preservatives on the accuracy of mid-infrared milk component testing. J. Dairy Sci. 93:6000-6011.

Broderick, G. A., and M. K. Clayton. 1997. A statistical evaluation of animal and nutritional factors influencing concentrations of milk urea nitrogen. J. Dairy Sci. 80:2964-2971.

Burgos, S. A., J. G. Fadel, and E. J. DePeters. 2007. Prediction of ammonia emission from dairy cattle manure based on milk urea nitrogen: Relation of milk urea nitrogen to urine urea nitrogen excretion. J. Dairy Sci. 90:5499-5508.

Hof, G., M. D. Vervoorn, P. J. Lenaers, and S. Tamminga. 1997. Milk urea nitrogen as a tool to monitor the protein nutrition of dairy cows. J. Dairy Sci. 80:3333-3340.

Jonker, J. S., R. A. Kohn, and J. High. 2002a. Dairy herd management practices that impact nitrogen utilization efficiency. J. Dairy Sci. $85: 1218-1226$

Jonker, J. S., R. A. Kohn, and J. High. 2002b. Use of milk urea nitrogen to improve dairy cow diets. J. Dairy Sci. 85:939-946.

Kohn, R. A., K. R. French, and E. Russek-Cohen. 2004. A comparison of instruments and laboratory used to measure milk urea nitrogen in bulk-tank milk samples. J. Dairy Sci. 87:1848-1853.

Lean, I. J., P. Celi, H. Raadsma, J. McNamara, and A. R. Rabiee 2012. Effects of dietary crude protein on fertility: Meta-analysis and meta-regression. Anim. Feed Sci. Technol. 171:31-42.

Luzzana, M., and R. Giardino. 1999. Urea determination in milk by a differential $\mathrm{pH}$ technique. Le Lait, INRA Editions 79:261-267.

Nousiainen, J., K. J. Shingfield, and P. Huhtanen. 2004. Evaluation of milk urea nitrogen as a diagnostic of protein feeding. J. Dairy Sci. 87:386-398.

Peterson, A. B., K. R. French, E. Russek-Cohen, and R. A. Kohn. 2004. Comparison of analytical methods and the influence of milk components on milk urea nitrogen recovery. J. Dairy Sci. 87:17471750.

Powell, J. M., C. A. Rotz, and M. A. Wattiaux. 2014. Potential use of milk urea nitrogen to abate atmospheric nitrogen emissions from Wisconsin dairy farms. J. Environ. Qual. 43:1169.

Roy, B., B. Brahma, S. Ghosh, P. K. Pankaj, and G. Mandal. 2011. Evaluation of milk urea concentration as useful indicator for dairy herd management: A review. Asian J. Anim. Vet. Adv. 6:1-19.

SAS Institute Inc.. 2003. SAS/STAT User's Guide: Statistics, Version 8 Edition. SAS Inst. Inc., Cary, NC.

Trevaskis, L. M., and W. J. Fulkerson. 1999. The relationship between various animal and management factors and milk urea, and its association with reproductive performance of dairy cows grazing pasture. Livest. Prod. Sci. 57:255-265.

Weeks, H. L., T. W. Frederick, L. M. Hagan, K. Heyler, J. Oh, and A. N. Hristov. 2015. Case Study: Farm-level evaluation of implementing nitrogen and phosphorus feeding best management practices on Pennsylvania dairy farms. Prof. Anim. Sci. 31:473-483. 